\title{
Reflexões Atuais Sobre Dependência Química e Aprisionamento: uma Discussão a Partir do Estado da Arte Entre os Anos de 2005 a 2017
}

\section{Current Reflections about Chemical Dependency and Imprisonment: a Discussion from the State of Art between 2005 and 2017}

\author{
Alessandra Siqueira Santos*a; Paulo Roberto Haidamus de Oliveira Bastos ${ }^{\mathrm{a}}$
}

aUniversidade Federal do Mato Grosso do Sul, Programa de Pós-Graduação em Saúde e Desenvolvimento na Região Centro-Oeste. MS, Brasil. *E-mail: alessandraciqbar@hotmail.com

\begin{abstract}
Resumo
As políticas públicas brasileiras, em especial, as que tratam da questão da dependência química na saúde, não obstante têm sido norteadas na atualidade por discursos ideológicos e reducionistas. Os custos sociais, emocionais e econômicos causados pela doença tendem a aumentar enquanto o foco estiver em soluções de cunho imediatista. Com isto, o encarceramento por tráfico de drogas se intensifica visivelmente e se constata a relação com o consumo de drogas ilícitas e sua criminalização, sendo este cenário, significativamente, fomentado ainda pela relação entre drogas, violência, aprisionamento e, reincidência penitenciária. No estudo em questão se procurou observar à luz dos trabalhos pesquisados a forma de condução das estratégias voltadas à dependência química e ao indivíduo vulnerável e, por vezes, em situação de aprisionamento. Trata-se de estudo na forma do "Estado da Arte" ou "Estado do Conhecimento" como método, sobre a relação da dependência química e aprisionamento. A pesquisa e levantamento do material foram realizados entre novembro de 2018 a março de 2019 , nos bancos de dados: SciELO, Pubmed, Lilacs, Medline e Capes, sendo a amostra final composta por dez estudos. As discussões em torno da dependência química devem ser pautadas em políticas públicas acessíveis que possam viabilizar os aspectos biopsicossociais que permeiam o indivíduo em vulnerabilidade, de forma a torná-las estratégias assertivas no tratamento da doença.
\end{abstract}

Palavras-chave: Usuário de Drogas. Drogas Ilícitas. Prisões e Sistema Penitenciário.

\begin{abstract}
The Brazilian public policies, especially those dealing with chemical dependence issues have been currently guided by ideological and reductionist discourses. The social, emotional and economic costs caused by the disease tend to increase as long as the focus is on immediate solutions. Thereby, the incarceration for drug trafficking has visibly intensified and the relationship between illicit drugs use and criminalization is also evident, being this scenario significantly fomented still by the relationship among drugs, violence, imprisonment and penitentiary recidivism. In the study in question, it was tried to observe in the light of the researched studies the way of conducting the strategies focused on chemical dependence and the vulnerable person and sometimes in prison situation. It is a study in the form of the "State of Art" or "State of Knowledge" as a method, on the relationship of chemical dependency and imprisonment. The material research and survey were conducted from November 2018 to March 2019, in SciELO, Pubmed, Lilacs, Medline and CAPES databases, and the final sample consisted of ten studies. Thus, it was concluded that discussions about chemical dependence should be guided by accessible public policies that can enable the biopsychosocial aspects that permeate the individual in vulnerability, in order to make them assertive strategies in the disease treatment.
\end{abstract}

Keywords: Drug User. Illicit Drugs. Prisons and Penitentiary System.

\section{Introdução}

A história da dependência de drogas se confunde com a própria história da humanidade e, portanto, remete a necessidade de buscar elementos na conjuntura sócio históricoculturais que sejam capazes de esclarecer ou ao menos denotar as causas do desenvolvimento de diferentes padrões de consumo de substâncias psicoativas e, consequentemente, o alastramento com que ocorre a doença (CARRANZA; PEDRÃO, 2005).

Atualmente, a Organização Pan-Americana de Saúde e a Organização Mundial de Saúde (OPAS/OMS, 2017) têm expressado preocupação em relação às ações e ao controle no alastramento mundial da dependência química. De acordo com o Relatório Mundial sobre Drogas (2018) do Escritório das Nações Unidas sobre Drogas e Crime (UNODC), o uso excessivo de drogas no mundo tem sido considerado um expressivo problema de saúde pública. Sendo assim, é preciso que a política pública de saúde mental no Brasil estabeleça estratégias de promoção, de prevenção e de tratamento que sejam consonantes ao estabelecido por estas organizações e que por fim sejam estas acessíveis e aplicáveis para a população privada de liberdade (LIMA; LIMA, 2015).

O documento emitido pelo UNODC (2018) concluiu que o mercado de drogas ilícitas se expande significativamente. Dados estatísticos apresentados, neste estudo, mostraram que cerca de $76 \%$ dos casos de mortes envolvem distúrbios relacionados ao uso de drogas, em especial pelas opioides, haja vista o crescimento da produção do ópio e da cocaína. Ainda neste relatório, são citados também estudos com dados relevantes apresentados em 2016 em relação ao uso de cannabis, a qual foi considerada a droga mais consumida no referido ano, com 192 milhões de pessoas que a utilizaram 
ao menos por uma vez no período pesquisado. Informações dessa natureza demonstram que novas frentes precisam surgir para lidar com os desafios contemporâneos (MARTINELLI, 2015).

Tal reflexão em torno da dependência química e sua relação com a situação de aprisionamento se torna primordial para o desenvolvimento de novos métodos e práticas interventivas que poderão atuar como fomentadores de políticas públicas mais articuladas e condizentes aos aspectos inerentes à doença e ao indivíduo acometido, tal qual preconizado pelos parâmetros de atuação da OPAS/OMS (2017).

As políticas públicas precisam ser pensadas enquanto estratégias de promoção, de prevenção e de tratamento o que significa torná-la acessível e aplicável também para a população privada de liberdade, dessa forma atendendo as expressões da questão social brasileira (IAMAMOTO, 2009)

Em face do demonstrado, este estudo buscou analisar dentre os dez estudos selecionados desde o cenário adverso ao brasileiro até trazê-lo para o contexto em si, buscando compreender as formas de organização e atuação para a discussão e tratamento da dependência química, para tal, fazendo uso do "Estado da Arte" ou também como é reconhecido "Estado do Conhecimento" (DEGASPERI, 2013).

Assim, torna-se necessário diante ao exposto propor uma reflexão destituída de ideologias e reducionismos, de como o uso de drogas ilícitas chegou à condição de doença mental e fenômeno social influenciando por vezes, de maneira direta, a inserção do indivíduo adoecido a situação de prisão (LARANJEIRA, 2010; TAVARES, ALMEIDA, 2010).

\section{Desenvolvimento}

\subsection{Metodologia}

Trata-se de estudo na forma do "Estado da Arte" ou
"Estado do Conhecimento" como método, sobre a relação da drogadição e aprisionamento (FERREIRA, 2002). A pesquisa e levantamento do material foram realizados entre os meses de novembro de 2018 a março de 2019, nos bancos de dados: SciELO, PubMed, Lilacs, Medline e Capes, sendo considerados os descritores em saúde (DeCS) na Língua Portuguesa e Inglesa: usuário de drogas, dependência química, drogas ilícitas, prisões e sistema penitenciário.

Foram incluídos estudos publicados no período de 2005 a 2017, estes estudos por abordarem a temática proposta e responder o seguinte questionamento: existe relação entre a dependência química e a condição de aprisionamento da pessoa vulnerabilizada pelo uso de drogas? No total, para atender o intuito deste trabalho foram consultados e analisados 143 trabalhos científicos, entre livros, teses de doutorado, dissertações de mestrado e artigos.

A partir destes, dez trabalhos que contribuíram para a temática da dependência química foram selecionados, com estes foi feito uso das construções e descobertas adquiridas de modo a utilizá-los como contribuição à elaboração do presente artigo. Durante o processo investigativo se buscou identificar trabalhos desenvolvidos em torno da temática da dependência química e, possível relação com o aprisionamento.

Ainda com relação ao material pesquisado, foram incluídos também trabalhos que, embora não discutam a dependência química em pessoas privadas de liberdade e nem mesmo as reincidentes prisionais, abordam a questão com enfoque nos aspectos biopsicossociais e também sob o ponto de vista jurídico legal, assim, se tornam relevantes para a busca de uma leitura da problemática que vise ir além das discussões de cunho reducionistas ou meramente ideológicas.

Portanto, o uso que se fez destes e dos demais trabalhos consultados foi no sentido de fundamentar os aspectos que serão apresentados acerca da questão principal para enfim construir esta produção, exemplificado no Quadro 1.

Quadro 1 - Estudos Portugueses e Brasileiros acerca da Dependência Química e do aprisionamento dos anos de 2005 a 2017

\begin{tabular}{|c|c|c|c|c|}
\hline Autor & Ano & Tipo & Descritores & Resultados \\
\hline $\begin{array}{c}\text { Anália Cardoso Torres } \\
\text { e Maria do Carmo } \\
\text { Gomes }\end{array}$ & 2005 & Artigo & $\begin{array}{c}\text { Substâncias psicoativas } \\
\text { presidiários, prisões, } \\
\text { consumo de drogas }\end{array}$ & $\begin{array}{c}\text { Esboçou pistas interpretativas para a compreensão das } \\
\text { relações entre drogas, pobreza e reclusão. }\end{array}$ \\
\hline $\begin{array}{c}\text { Wilian Custódio Lima, } \\
\text { Wedner Custódio Lima }\end{array}$ & 2005 & Artigo & $\begin{array}{c}\text { Concluiu que a mídia reproduz um paradoxo nas } \\
\text { Crídia, Sistema Prisional } \\
\text { proposições relativas às políticas de encarceramento } \\
\text { e, que uma reflexão sobre as drogas poderia } \\
\text { equacionar uma quebra de paradigma na política } \\
\text { criminal brasileira. }\end{array}$ \\
\hline $\begin{array}{c}\text { Gislaine Pereira } \\
\text { Martins de Almeida }\end{array}$ & 2010 & Artigo & $\begin{array}{c}\text { Crime, Drogas, Homens, } \\
\text { Prisões, Violência }\end{array}$ & $\begin{array}{c}\text { Concluiu que a violência e a dependência de drogas } \\
\text { estão diretamente relacionadas em prisioneiros. }\end{array}$ \\
\hline $\begin{array}{c}\text { Rafael Rodrigues } \\
\text { Sanches }\end{array}$ & 2010 & Dissertação & $\begin{array}{c}\text { Drogas, criminalização, } \\
\text { proibicionismo }\end{array}$ & $\begin{array}{c}\text { Reafirma a percepção de que o proibicionismo } \\
\text { inviabiliza possibilidades de debates e transformações } \\
\text { a um controle criminal e a complexa questão das } \\
\text { drogas. }\end{array}$ \\
\hline Ronaldo Laranjeira & 2010 & Artigo & $\begin{array}{c}\text { Drogas e saúde pública, } \\
\text { Drogas e } \\
\text { sociedade, Políticas sobre } \\
\text { drogas }\end{array}$ & $\begin{array}{c}\text { Análise da política sobre drogas no Brasil no enfoque } \\
\text { da saúde pública. }\end{array}$ \\
\hline
\end{tabular}




\begin{tabular}{|c|c|c|c|c|}
\hline $\begin{array}{c}\text { Helena Salgueiro } \\
\text { Lermen, Tamires } \\
\text { Dartora, Carine Capra- } \\
\text { Ramos }\end{array}$ & 2014 & Artigo & $\begin{array}{l}\text { drogas, sistema prisional, } \\
\text { abstinência, redução de } \\
\text { danos }\end{array}$ & $\begin{array}{l}\text { Evidenciou a existência de ações que preconizam } \\
\text { a abstinência total em detrimento da estratégia de } \\
\text { redução de danos }\end{array}$ \\
\hline $\begin{array}{l}\text { Marcelo da Silveira } \\
\text { Campos }\end{array}$ & 2015 & Tese & $\begin{array}{c}\text { Dispositivo, nova lei de } \\
\text { drogas, congresso nacional, } \\
\text { sistema de justiça criminal, } \\
\text { lei } 11343 / 2006\end{array}$ & $\begin{array}{c}\text { Apresentou que há uma nova maneira de } \\
\text { administração estatal da droga no Brasil, qual é a sua } \\
\text { história e como ela desenvolveu práticas no sistema } \\
\text { de justiça criminal. }\end{array}$ \\
\hline Priscila Flores Prates & 2016 & Dissertação & $\begin{array}{l}\text { Substâncias psicoativas } \\
\text { presidiários, prisões, } \\
\text { consumo de drogas }\end{array}$ & $\begin{array}{c}\text { Demonstrou que há uma associação fortemente } \\
\text { estabelecida entre uso de drogas e a privação de } \\
\text { liberdade, causando problemas de saúde e de } \\
\text { segurança }\end{array}$ \\
\hline $\begin{array}{l}\text { Luis Flávio Sapori, } \\
\text { Roberta Fernandes } \\
\text { Santos, Lucas Wan Der } \\
\text { Maas } \\
\end{array}$ & 2017 & Artigo & $\begin{array}{l}\text { Reincidência criminal; } \\
\text { prisão; crime; punição; } \\
\text { segurança pública }\end{array}$ & $\begin{array}{l}\text { Identificação do perfil dos presos reincidentes } \\
\text { em comparação com o dos não reincidentes, } \\
\text { demonstrando possíveis fatores individuais }\end{array}$ \\
\hline $\begin{array}{l}\text { Clayton Ezequiel dos } \\
\text { Santos }\end{array}$ & 2017 & Tese & $\begin{array}{l}\text { Descriminalização Drogas } \\
\text { Políticas Públicas - } \\
\text { Portugal. Políticas Públicas } \\
\text { - Brasil. Usuários de } \\
\text { Drogas }\end{array}$ & $\begin{array}{l}\text { Demonstrou a importância de as ações no contexto } \\
\text { brasileiro serem menos identificadas com a Saúde } \\
\text { Mental, a necessidade de diversificar os locais de } \\
\text { intervenção e atuar com outras populações fora do } \\
\text { registro das dependências }\end{array}$ \\
\hline
\end{tabular}

Fonte: Dados da Pesquisa.

\subsection{Discussão}

\subsubsection{A Política Pública de Saúde Portuguesa e suas Práticas - Contribuição no Brasil}

Santos (2017) traçou um paralelo entre a rede de cuidados desenvolvida em Portugal com a atual política pública de saúde. É justamente neste aspecto que se aponta distinção significativa de como Portugal e o Brasil conduzem a questão das drogas, afirmando que, com relação à lei de drogas brasileira de 2006 é possível se identificar um descompasso entre a intenção e a operacionalização da mesma, que expõe a ausência de critérios e maior clareza em seu contexto, dificultando assim sua aplicabilidade.

No que tange ao principal objetivo do trabalho, o autor ponderou diferenciações significativas referentes à rede de atenção, visto que a organização e estrutura brasileira demonstram não comportar, no momento, a efetivação de uma rede de cuidados potencialmente eficiente no que se refere à questão das drogas, pois se limitam aos atendimentos ambulatoriais sem visíveis indicativos de mudanças nas estratégias (BRASIL, 2010).

Na mesma vertente, Torres e Gomes (2005) referem suas considerações e constatações como sendo pistas interpretativas que conduzem ao entendimento da relação entre pobreza, drogas e a reclusão, e ainda destaca que tal associação pode ser observada em muitos países, como: Bélgica, Alemanha, Espanha, Suécia, Inglaterra, Áustria, Grécia entre outros, enfocando que nestes o consumo de drogas na população reclusa está acima de 50\%. É fato que não se pode classificar todo e qualquer usuário como dependente químico ou abusador de drogas ilícitas, afinal alguns destes consumidores sequer chegam a se tornar dependentes químicos, pois limitam seu uso de maneira recreativa e esporádica, em festas ou apenas para experimentação.

Porém, não é o caso da maioria dos indivíduos que consumiam drogas em meio livre e que acabaram por fazer parte da massa carcerária portuguesa. Neste caso específico, as investigações demonstraram expressivo quantitativo de reclusos que acabaram por se tornar dependentes químicos e ainda mais, teve que cometer crimes para manter o vício, o que fatalmente acaba por vezes em reconduzi-los ao sistema prisional (TORRES; GOMES, 2005).

No estudo apresentado foi demonstrado que, de maneira direta ou indireta, a situação de aprisionamento estava $72,9 \%$ relacionado às drogas. Com isto, as autoras buscaram compreender a origem de tamanha expressividade e observaram ser a lógica da delinquência um fator específico para tais conclusões. A situação de pobreza das famílias quando agregado a ausência de sucesso na vida escolar e a dificuldade para inserção ao trabalho qualificado acabam por remeter o jovem a segmentos de labor, que não exigem qualificações profissionais e se baseiam em sua maioria a serviços braçais ou meramente mecânicos, sendo, portanto, mal remunerados. Neste contexto, as oportunidades para o envolvimento em ambientes que favorecem o contato com as drogas e o início de atividades delinquentes é uma espécie de roteiro previamente traçado (TORRES; GOMES, 2005).

A questão da reincidência prisional demonstra uma expressiva relação com a questão das drogas, e os estudos mostraram que $80,3 \%$ dos reincidentes estão envolvidos com crimes relacionados com as drogas. As autoras ainda referem que tal dado se deve ao fato de que esta população que já detém recursos escassos, tem suas vulnerabilidades ainda mais acentuadas quando em meio livre, pois mantém sua condição de parca escolaridade, ausência de qualificação profissional, vivência em meio prisional e, sendo agregada a estes fatores a questão de sua vulnerabilidade com as drogas que, fatalmente, dificultam sua efetiva inserção social (TORRES; GOMES, 2005).

A probabilidade desses indivíduos, com o histórico citado, 
serem reinseridos no sistema prisional é significativa, até mesmo quando considerada a exposição a qual os mesmos por vezes se colocam, seja na prática de delitos, seja em busca de consumir drogas, que geralmente ocorrem em regiões notoriamente conhecidas pelas autoridades policiais. (TORRES; GOMES, 2005).

\subsubsection{Lei de Drogas e a intensificação do encarceramento no Brasil}

Campos (2015), por sua vez, volta o olhar para as implicações da legislação sobre drogas no contexto do Sistema da Justiça Criminal de São Paulo, referindo que esta lei (BRASIL, 2006) busca atuar como um dispositivo médico criminal de drogas. Evidencia o teor punitivo e criminalizador para os comerciantes de drogas (traficantes) e a dimensão médica e de saúde para os que fazem uso das substâncias psicoativas ilícitas.

Em um segundo momento, o estudo é voltado para a questão da intensificação do encarceramento por tráfico de drogas e pela constatação norteada, ainda que empiricamente, pelo processo que contemplava não apenas o tráfico, mas atingia também casos de uso de drogas, pois neste aspecto se inseria as incriminações decorrentes do consumo das mesmas. Assim, percebe-se que a dimensão ligada à parte médica/ saúde tem sido preterida em função da justiça criminal que claramente rejeita a possibilidade de deslocar o usuário de drogas para o sistema de saúde, tornando assim possível sua retirada do sistema prisional (CAMPOS, 2015).

Nesse sentido, a intensificação do encarceramento se deve não apenas a indistinção entre traficantes e usuários, mas também na dificuldade em se estabelecer novas práticas e novos saberes em torno da questão (CAMPOS, 2015; MARTINELLI, 2015).

\subsubsection{O modelo proibicionista no contexto brasileiro}

Sanches (2010) demonstra a necessidade de desconstruir o modelo proibicionista e criminalizador de drogas. Refere ser a estratégia da redução de danos a mais viável e racional para a redimencionalização das políticas sobre drogas, para a administração da circulação destas substâncias e para o enfrentamento da violência. Ainda, pontua que é premente a superação do paradigma da guerra as drogas, e que este deve ser superado para que não mais haja tolhimentos no mínimo "obscurantistas" e para que a pluralidade da "aventura humana" tenha enfim sua liberdade.

É feita uma discussão em torno das drogas de maneira reducionista e voltada meramente aos aspectos econômicos e políticos da proibição das drogas, fazendo menção ao tratado de Haia (1912). O enfoque se torna centrado no cenário internacional, desde disputas geopolíticas e econômicas até a questão das drogas propriamente (SANCHES, 2010).

No contexto de seu trabalho, Sanches (2010), ao trazer a discussão para o cenário brasileiro, cita uma pesquisa realizada no ano de 2009 , a qual demonstrou que $67 \%$ das pessoas condenadas por tráfico de drogas eram primárias e detinham pouca quantidade de droga consigo, sem demonstrarem associação com o crime organizado. Torna-se relevante destacar que à época de tal pesquisa, não havia ainda a expansão das facções criminosas.

Quando busca demonstrar a ineficiência do modelo proibicionista, o autor o faz associando a interesses exclusivamente políticos e econômicos, com ênfase na realidade sociocultural marcada entre os séculos XVI a XIX, quando o Brasil acatou o paradigma do proibicionismo pósconvenção política e não exatamente porque à época esta fosse uma problemática existente. A partir de então, as legislações brasileiras se adequaram e passaram a contemplar o que era internacionalmente convencionado.

\subsubsection{A atuação da mídia no Sistema Prisional}

$\mathrm{Na}$ contextualização de Lima; Lima (2015) é dado enfoque na atuação da mídia no sistema prisional e em como esta compromete a produção científica explicando que, diante do paradoxo existente nesta relação, surgiram dificuldades para propor políticas eficientes de encarceramento no país, que considerem de forma clara e verdadeira o ambiente prisional. Os autores referem ainda a necessidade de quebra de paradigmas para melhor equacionar a questão do contexto da política criminal.

Traz um "olhar coletivo" voltado à questão das drogas em detrimento do "indivíduo adoecido". Contudo, mesmo que não trate diretamente da questão das drogas e sujeito aprisionado, reflete o quanto é necessário haver uma discussão pautada no consenso para a formulação de políticas viáveis e condizentes com a realidade (LIMA; LIMA, 2015).

Por fim, o estudo de Lima e Lima (2015) é centralizado em torno do sistema prisional e sua relação antagônica com o meio acadêmico, não produzindo assim elementos para a compreensão da ambiência sob o olhar do sujeito aprisionado e os reflexos que a dependência química, enquanto doença, trouxe para a vida deste indivíduo, justamente pela ausência de políticas pautadas nas concretudes vivenciadas no ambiente prisional.

\subsubsection{Os reflexos de possível legalização das drogas ilícitas no âmbito da saúde no Brasil}

Laranjeira (2010) procura avaliar a racionalidade em torno da questão da legalização de drogas sob o enfoque da saúde pública, bem como possíveis consequências em função disto. A ênfase dada pelo autor é no campo da saúde e, nos reflexos que podem ser acarretados com uma possível legalização. O estudo defende que o fervor ideológico deve ser substituído por um pragmatismo afiado e persistente para que as questões sejam embasadas em exemplos de experiências eficazes, que devem ir além da mera discussão "do contra e do a favor".

Os custos sociais, emocionais e econômicos causados pelas drogas, segundo o estudo, podem aumentar a cada dia e a procura por soluções imediatistas apenas dificulta a 
assertividade das estratégias. Um dos argumentos apresentados é de que a discussão não deve ser pautada apenas no ponto de vista jurídico, sendo a legalização para a saúde pública inviável.

Nesse sentido, ainda refere que inicialmente pode haver uma diminuição da violência individual, mas que a violência global pode aumentar significativamente, o que acarretará consequentemente no aumento de danos à sociedade. Ainda, aponta os reflexos causados pelo uso contínuo de drogas, fazendo ponderações de como estas atuam no sistema nervoso central (SNC) e as alterações que provocam (LARANJEIRA, 2010; RIBEIRO; LARANJEIRA, 2016). É enfatizada, pelo autor, a conexão entre cérebro e comportamento para explicar determinados aspectos apresentados pela doença.

Com relação às políticas relacionadas às drogas se afere que há notável dificuldade para analisar as mesmas e, nesse sentido, sustenta a importância de se considerar toda a complexidade da situação. Por fim, afirma que a problemática das drogas deve ser avaliada muito além dos parâmetros numéricos apresentados comumente, pois se difere de indivíduo para indivíduo e também de acordo com o meio social, o que torna irracional discutir a questão da legalização das drogas sem a análise fundamentada sob todos os aspectos inerentes à doença e da pessoa adoecida (LARANJEIRA, 2010; RIBEIRO; LARANJEIRA, 2016).

\subsubsection{Estudo sobre a reincidência e o uso de drogas no Estado de Minas Gerais}

Sapori, Santos e Maas (2017) apresentam resultados embasados em dados quantitativos, voltados para um estudo comparativo entre presos reincidentes e não reincidentes, do Estado de Minas Gerais nos anos de 2014 e 2015, os quais enfatizaram as características individuais dos apenados, como forma de explicar a motivação para a reincidência. Nesse sentido, os autores expõem que em estudos internacionais desenvolvidos em países europeus e norte-americanos existe uma vertente voltada para a compreensão dos aspectos sociológicos que são considerados como fatores de risco ao fenômeno da reincidência criminal. Tais estudos demonstraram que os egressos mais suscetíveis a reincidirem criminalmente são justamente aqueles que têm problemas com uso de drogas e de baixo nível de escolarização.

Tratando do fenômeno da reincidência criminal, no contexto brasileiro, Sapori, Santos e Maas (2017) contribuem de maneira relevante para a questão e enfatizam que, embora haja consolidado no pensamento jurídico e no senso comum de que a taxa de reincidência criminal no Brasil é superior a $70 \%$, não há verdadeiramente estudos de abrangência nacional que aborde a questão.

Os autores buscaram elementos baseados em cálculos sobre as taxas de reincidência criminal assim como fatores de ordem sociodemográfica que podem atribuir distinções qualitativas entre o perfil do preso reincidente com o não reincidente (SAPORI; SANTOS; MAAS, 2017).

O estudo de Sapori, Santos e Maas (2017) demonstrou que a taxa de reincidência criminal em Minas Gerais foi de 51\%, considerando para tal os registros entre os anos de 2008 a 2015. Comparativamente, os autores apresentam que estudos de Adorno e Bordini (1986), entre os anos de 1974 e 1986, neste aspecto, aferiram um índice de $46 \%$ no Estado de São Paulo e, as conclusões de Lemgruber (1989) que mensurou no ano de 1988 um quantitativo de reincidentes de $31,6 \%$ no Rio de Janeiro.

Destacam a primeira pesquisa sobre reincidência criminal realizada pelo Instituto de Pesquisa Econômica e Aplicada (IPEA, 2015), como trabalho de grande relevância, por tratarse de estudo que adotou a metodologia quantitativa aliada a metodologia qualitativa, com a intenção de aprofundar os conhecimentos inerentes à implementação de ações voltadas à reintegração social (SAPORI; SANTOS; MAAS, 2017).

Dessa forma, estudos desta natureza remetem a imperatividade em passar a tratar a dependência química como doença que efetivamente compromete a vida do indivíduo por essa acometido e, principalmente, se for este indivíduo egresso do sistema penitenciário. Políticas públicas pautadas em concretudes são emergentes para o devido enfrentamento do fenômeno da drogadição nas prisões (SAPORI; SANTOS; MAAS, 2017).

\subsubsection{O consumo de substâncias ilícitas em Unidades prisionais}

Prates (2016) investiga, por meio de aplicação de testes, o consumo de substâncias ilícitas em homens privados de liberdade. Remete o uso abusivo de drogas e a própria dependência química como problemas de saúde pública nacional e, ainda, salienta que embora relevante a temática, essa não é amplamente abordada.

Embora o estudo se restrinja a descrever o uso/abuso de substâncias ilícitas apenas dentro da unidade prisional, sem buscar fatores possivelmente condutores do fenômeno da dependência química, ainda assim se torna relevante por apresentar dados respaldados em testes psicológicos. O estudo demonstrou por meio da aplicação dos testes que a taxa de uso, de abuso e de dependência em maconha ultrapassaram $80 \%$ entre os participantes da pesquisa, sendo que no caso da cocaína e do crack o número alcançou 67,6\% (PRATES, 2016).

$\mathrm{Na}$ discussão dos dados, Prates (2016) apresenta informações nos gráficos que divergem do contexto, o que torna o trabalho no mínimo passível de uma revisão para republicação. Ocorreu a percepção de que os participantes em determinados momentos apresentavam informações que negavam a existência de drogas ilícitas na prisão, fato este passível de se vislumbrar diante da linearidade do dado de $7,9 \%$ que informavam no transcorrer do estudo que não havia drogas dentro do presídio. 
Por fim, Prates (2016) finaliza seu estudo afirmando que foi possível perceber que há o consumo de substâncias ilícitas na prisão, inclusive de forma concomitante a outras drogas e que a ausência de propostas voltadas ao tratamento da dependência química em pessoas privadas de liberdade dificulta a superação da vulnerabilidade adquirida.

Lermen, Dartora e Capra-Ramos (2014) analisaram um projeto voltado à desintoxicação de drogas que é destinado aos privados de liberdade no Estado do Rio Grande do Sul. No estudo foi referido ainda que não diretamente, que o trabalho em questão vai na "contramão" da estratégia de redução de danos. Nesse sentido, é apresentada uma contextualização acerca da política proibicionista historicamente adotada pelo Brasil, assim como as influências advindas, posteriormente, com subsídios científicos que passaram a caracterizar a drogadição como doença patologicamente reconhecida (DSM $5,2013)$.

É referido pelos autores que embora sejam modelos distintos, o tratamento em ambos era pautado na abstinência completa e, assim, apresentaram a estratégia de redução de danos como alternativa a estes modelos. Enquanto defesa da redução de danos, argumentam que a vulnerabilidade dos sujeitos se deve à falta de informação e/ou informações equivocadas, bem como as dificuldades que estes sujeitos apresentam ao tentar incorporar estas práticas em seu contexto.

Ao considerarem que o indivíduo adoecido deve ser analisado diante de uma perspectiva biopsicossocial, Lermen, Dartora e Capra-Ramos (2014) demonstram contradição, pois o estudo afirma que uma estratégia apenas, que no caso é a de redução de danos é a mais viável, deixando neste momento de buscar compreender a complexidade da doença e do indivíduo, anulando assim a possibilidade de conceber como mais assertiva a aplicação de múltiplas estratégias que poderiam vir a se inter-relacionar e não se contraporem no contexto de tratamento da dependência química.

Percebe-se que no estudo, ao ser criticado a ausência da estratégia de redução de danos no ambiente prisional não foi considerada uma questão fundamental, tal como a ilegalidade de tais substâncias. Foi evidenciado o quanto é ignorado as percepções do indivíduo encarcerado diante do intuito de fazer com que prevaleça o entendimento de que a estratégia de redução de danos é a mais viável.

\subsubsection{O consumo de drogas enquanto facilitador da violência}

Tavares e Almeida (2010) descreveram a relação do uso de drogas com a violência, apresentando o consumo destas substâncias ilícitas como facilitador importante para as situações violentas e que, por vezes, podem acabar desencadeando a situação de prisão. O estudo refere que a origem do comportamento violento requer ainda maiores esclarecimentos. Contudo, se observou que o controle dos impulsos agressivos está diretamente ligado à preservação do sistema nervoso central, que não pode estar comprometido por doenças ou uso de drogas, caso contrário, a capacidade de avaliar a realidade com base em seu juízo crítico preservado pode estar comprometido.

Os autores apontaram que muito embora as consequências do uso de drogas venham a depender de fatores de ordem individual, social e cultural, ainda assim, podem ser associados a estímulos, respostas, motivos ou demais elementos que atuam como mediadores de comportamentos violentos e, ainda, que o contexto no qual estas substâncias são utilizadas acaba por sofrer influências diante da evidência do uso.

Na contramão do que muitos descrevem como o "terrorismo preconizado pelo proibicionismo as drogas", o estudo ressaltou que nem todo usuário virá a se tornar um dependente químico, pois é preciso considerar as variâncias existentes de indivíduo para indivíduo, muitas vezes demonstrados por fatores de ordem biopsicossocial e que precisam ser criteriosamente analisados (TAVARES; ALMEIDA, 2010).

Nesse sentido, esses estudos pontuam que dada à complexidade da relação das drogas com a violência se observou que em ambientes nos quais a violência é mais “aceita" poderá haver um índice de maior criminalidade e de consumo de substâncias ilícitas. Enfatizam que os sujeitos que vivenciam este contexto de aceitação da violência acabam ficando mais expostos às situações de ordem social e cultural, em que o consumo de drogas ilícitas pode ser ora banalizadas, ora estimuladas e, destacaram que a existência da associação entre a violência e a ausência de controle do uso de substâncias ilícitas está presente tanto antes do ato de consumir quanto posterior a esse (TAVARES; ALMEIDA, 2010).

Ainda neste estudo, ao ser apresentado fator de risco para o desencadeamento de transtornos mentais foi enfatizada a importância de não haver uma avaliação isolada, em que apenas determinado aspecto é considerado. Nessa direção, remetem tal entendimento também para a compreensão da dependência química que pode vir a se desencadear em função de múltiplos fatores, de ordem genética, social, neurofuncional, ausência de vínculos sociais e familiares, não aceitação de tratamento e tantos outros fatores biopsicossociais que requerem atenção para a compreensão enquanto doença e fenômeno social (TAVARES; ALMEIDA, 2010).

\subsubsection{Discussão acerca da dependência química no Brasil}

Após a breve apresentação dos trabalhos selecionados e seus principais aspectos, será neste momento evidenciada a contribuição de cada um desses para a construção deste artigo que objetiva discutir acerca da possível relação entre dependência química e aprisionamento.

Sendo assim, buscou-se em trabalhos desenvolvidos em Portugal por Santos (2017) e por Torres; Gomes (2005) referências de como o país conduz sua política pública de saúde, assim como a atenção que é dada a questão da dependência química, suas intervenções e produção do conhecimento sobre a temática. Estes autores evidenciaram que Portugal apresenta uma estrutura que difere essencialmente da brasileira. 
Ao tratar a dependência química como doença e evidenciar que a lei de descriminalização das drogas não alterou de forma significativa o consumo de substâncias ilícitas e suas variantes, Santos (2017) ressalva que Portugal passou a traçar estratégias articuladas entre as políticas públicas, considerando assim como indissociáveis políticas de saúde mental e o campo jurídico.

Com relação à dependência química no ambiente prisional, Torres; Gomes (2005) demonstraram em sua pesquisa o quanto é relevante compreender o indivíduo aprisionado e dependente químico para além dos dados quantitativos e estatísticos. Evidenciaram aspectos que não diferem, significativamente, de outros países, inclusive do âmbito brasileiro, quando analisada a situação de aprisionamento, que gira em torno do consumo de drogas, seguido pela baixa escolaridade e ausência de qualificação profissional.

No contexto brasileiro se procurou destacar as discussões que permeiam a temática sobre as drogas, que de forma geral é em torno da reformulação da lei de drogas, o modelo proibicionista versus uma possível legalização de substâncias ilícitas e breves relances sobre uma política de saúde mental que demonstre maior assertividade do que as apresentadas até o momento.

Campos (2015) procura destacar que é visível o quanto se intensificou o encarceramento com a lei de drogas até então vigente. Ressalta que a formulação da lei foi norteada por discursos científicos e moralistas, com evidente teor punitivo. Tornou-se evidente, portanto, o quanto a parte médica/saúde tem sido preterida em função da justiça criminal. Nesse sentido, é fundamental destacar o visível distanciamento entre a legislação brasileira e a portuguesa, que de maneira assertiva tem buscado a articulação com as políticas públicas e o poder judiciário como ferramenta essencial no enfrentamento da dependência química.

No concernente a temática sobre drogas, não eventualmente surgem discursos de cunho ideológico e reducionista, que discorrem em torno do fracasso do modelo proibicionista e o que seria a salvação, no caso, a legalização das substâncias ilícitas até então.

Com este enfoque, Sanches (2010) desenvolve seu trabalho citando estudos ultrapassados, que ignoram pesquisas notoriamente reconhecidas em torno dos malefícios de substâncias psicoativas quanto utilizadas com finalidade alheia a tratamentos de saúde. Discorre acerca de fatores políticos e econômicos que não têm relevância no cenário brasileiro, mas que de acordo com o autor, têm relação direta com os meios de produção e consumos de drogas ilícitas.

Assim, ao embasar seu estudo em pontuações alheias ao momento e a realidade brasileira, Sanches (2010) não apresenta indicativos sólidos de como a estratégia de redução de danos poderia vir a ser efetivada e reconhecida como alternativa viável e eficiente no tratamento da dependência química.

Segundo Lima e Lima (2015), a relação da mídia com o sistema prisional por vezes corrobora para a ausência de produções científicas e políticas públicas pautadas em concretudes. Os autores não relacionam diretamente a questão das drogas e o sujeito aprisionado em seu trabalho, contudo se mostrou relevante a este estudo por demonstrar, em linhas gerais, que a atuação da mídia pode influenciar tanto na formulação de políticas quanto nas intervenções adotadas.

É também destacado por Laranjeira (2010) que uma possível legalização para as drogas, a princípio e de forma individual, pode até promover uma diminuição da violência, mas que do ponto de vista global a mesma pode aumentar significativamente. Ainda, para corroborar, Ribeiro e Laranjeira (2016) apontam as consequências do uso contínuo de substâncias psicoativas no sistema nervoso central (SNC) e enfatizam a conexão existente entre o cérebro e o comportamento para discorrer sobre os aspectos da doença, reafirmando assim os pontos de vista já estudados em Laranjeira (2010).

Quanto às políticas sobre drogas, esses estudos referem que há notável dificuldade em se analisar as mesmas, haja vista que observam não haver, no contexto destas, a complexidade que envolve a dependência química enquanto doença e fenômeno social. Tal fator é um dos impedimentos para avaliações coerentes, que se relacionam ao consumo de substâncias psicoativas, que em geral apresentam dados numéricos e estatísticos, sem considerar o meio social, as ambiguidades da natureza humana e outros aspectos subjetivos. Tornase, portanto, irracional, dentro deste contexto discutir uma possível legalização das drogas.

Ainda, Laranjeira (2010) trouxe relevante contribuição para este estudo, haja vista demonstrar a coerência necessária para a discussão em torno da temática. No contexto de seu trabalho, embora escrito há quase uma década, o autor sob o ponto de vista da saúde pública faz ponderações lógicas e condizentes com o cenário atual, ao ponderar a necessidade de desenvolver pesquisas e estudos que não tratem apenas da dependência química, mas também dos reflexos do uso contínuo de drogas no sistema nervoso central (SNC) e sua relação com o comportamento humano. É justamente sob este enfoque que se procura ainda que sucintamente se debruçar, diante da necessidade de discutir profundamente sobre as complexidades da doença, do indivíduo e do meio ao qual emergem as vivências deste.

Sapori, Santos e Maas (2017) apresentam as conceituações que envolvem a reincidência criminal e, embora de natureza quantitativa, buscaram analisar as características individuais dos apenados, como forma de possibilitar a compreensão das reais motivações que os levaram a reincidir.

O estudo se torna significativo aos propósitos deste artigo por trazer em seu contexto a citação de pesquisas relevantes e concernentes a fatores que, possivelmente, tenham relação com a reincidência criminal, entre essas a pesquisa desenvolvida pelo Instituto de Pesquisa Econômica e Aplicada (2015) que demonstrou a relação do uso de drogas com a reincidência 
criminal nos cinco Estados da confederação brasileira que foram pesquisados (Paraná, Minas Gerais, Alagoas, Pernambuco e Rio de Janeiro).

É evidenciado no decorrer do trabalho que foi desenvolvido por Sapori, Santos e Maas (2017) que estudos desta natureza, pautados em concretudes, remetem o quanto é imperativo a discussão da temática da reincidência criminal e seus reais fatores condutores para que políticas públicas sejam enfim construídas e pautadas na realidade vivenciada pela sociedade. Foi também considerado para este trabalho, o estudo de Prates (2016) e de Lermen, Dartora e Capra-Ramos (2014) por apresentarem aspectos relacionados ao consumo de substâncias químicas ilícitas no interior de Unidades Prisionais brasileiras.

Os aspectos evidenciados no estudo de Prates (2016) foram baseados em testes psicológicos aplicados em pessoas privadas de liberdade, contudo, se observa que o intento era identificar as substâncias utilizadas e qual dessas era mais ou menos consumida. Não apresentou no contexto aspectos relativos às motivações, condicionantes ou estratégias de tratamento.

Ainda que seja destituído de critérios mais subjetivos e fatores externos ao ambiente prisional, o trabalho de Prates (2016) se torna relevante por demonstrar constatações embasadas em testes verificáveis e reconhecidos e, por concluir ao final que a ausência de propostas de tratamento dificulta a superação da vulnerabilidade causada pelas substâncias psicoativas ilícitas.

O enfoque apresentado por Lermen, Dartora e CapraRamos (2014) é voltado à proposta de desintoxicação de drogas realizada em privados de liberdade, em uma unidade prisional do Estado do Rio Grande do Sul. São visíveis as contradições apresentadas quanto ao tempo em que ponderam a eficiência da estratégia de redução de danos, afirmam que o tratamento requer uma múltipla abordagem decorrente da necessidade de considerar o indivíduo em todo seu contexto biopsicossocial. Ora, se a questão primordial for atuar em respeito às múltiplas peculiaridades de cada indivíduo, seria no mínimo questionável fazer uso de apenas uma estratégia de tratamento, independente de qual seja.

Embora não tenha sido enfatizado, o trabalho realizado na unidade prisional do Rio Grande do Sul demonstra conformidade com pesquisas apresentadas que evidenciam o quanto as mudanças de hábitos e de rotina são essenciais para a superação da vulnerabilidade com as drogas, bem como o entendimento da doença por parte do indivíduo que se encontra vulnerável em decorrência dessa.

Neste sentido, torna-se premente citar novamente Laranjeira (2010) que enfatiza a evidente conexão entre cérebro e comportamento, bem como a dificuldade que se tem ainda hoje em analisar as políticas relacionadas às drogas no Brasil, aspectos estes que são considerados apenas quando estiver em pauta discussões sobre a dependência química que seja alheia ao entusiasmo ideológico e reducionista que persistem ainda em torno da temática (RIBEIRO; LARANJEIRA, 2016; LARANJEIRA 2010).

Não por acaso, foi selecionado o estudo de Tavares e Almeida (2010) para dar fechamento para as considerações ora aqui apresentadas. Entre todos os trabalhos que compuseram este artigo, o estudo demonstra relevante contribuição para o intento aqui almejado, haja vista suas considerações e argumentações em torno da complexidade da dependência química em substâncias ilícitas e sua relação com a violência, aprisionamento e reincidência.

Os autores pontuam que a dimensão em torno da dependência química vai muito além de reflexões pontuais, afirmam ser necessário que o indivíduo seja compreendido e visto enquanto sujeito biopsicossocial, para passar a enxergálo em toda sua totalidade e complexidade, considerando seu contexto biopsicossocial de vivências e de experiências pregressas e atuais, sendo assim, foi observado que o controle dos impulsos nervosos está diretamente relacionado à preservação do sistema nervoso central, que não pode estar comprometido por doenças ou uso de drogas, do contrário a avaliação da realidade e o juízo crítico pode ser alterado (TAVARES; ALMEIDA, 2010).

Portanto, ainda concluem Tavares e Almeida (2010) que é preciso ir muito além de um ou outro modelo de tratamento. Ainda, nesse sentido, destacam a evidente relação entre o uso de drogas e a violência, pontuando haver nesse contexto uma evidente ligação com situações de prisão e reincidência prisional.

\section{Conclusão}

Os estudos evidenciaram cada qual sobre seu enfoque a forma como a dependência química vem sendo discutida na contemporaneidade, ora de maneira ideológica reducionista, ora sob os aspectos biopsicossociais que cercam o indivíduo em seu contexto vivencial. Embora nem todos os trabalhos tenham apresentado, de forma direta, a relação entre dependência química e aprisionamento, sendo premente destacar a relevância dos estudos que assim o fizeram, sendo de forma geral por estes finalizado que a mesma requer que as discussões sejam pautadas considerando toda a complexidade que a cerca, embora ainda hoje se vislumbre trabalhos com enfoque contrário.

Nesse sentido, o presente trabalho buscou analisar, entre os estudos selecionados, desde o cenário adverso ao brasileiro até trazê-lo para o contexto em si, buscando compreender as formas de organização e atuação para a discussão e tratamento da dependência química. No cenário brasileiro, ainda persistem estas discussões de cunho majoritariamente ideológico, do qual fica evidente que o intuito gira mais em torno de saber qual posicionamento prevalecerá do que exatamente qual estratégia atende mais assertivamente o problema em questão.

Observar a maneira de condução da política sobre drogas portuguesa, bem como sua produção de conhecimento e de estratégias de intervenção remete a reflexão do quanto ainda 
é preciso avançar para além das concepções pontuais e fragmentadas em torno da discussão da dependência química. Assim, é possível observar a relevância de uma política pública acessível e voltada a atender essencialmente as necessidades da população e o quanto discursos ideológicos e reducionistas inviabilizam sua existência.

Contudo, este estudo, ainda que na contramão da conjuntura observada, busca fomentar pesquisas e iniciativas que, embora ainda não tenham o devido reconhecimento para ganhar voz no ambiente político que define as tratativas e formulações das políticas públicas, demonstra o quanto fundamentada e estudada têm sido a questão da dependência química e sua relação com a violência e com a situação de aprisionamento, que pode assim ser considerada como reflexo da questão social brasileira.

\section{Referências}

ADORNO, S.; BORDINI, E. Reincidência e reincidentes penitenciários em São Paulo - 1974 a 1985. Rev. Bras. Ciênc. Soc., v.9, n.3, p.70-94. 1986.

AMERICAN PSYCHIATRY ASSOCIATION. Diagnostic and Statistical Manual of Mental disorders. DSM-5, 2016.

BRASIL, Ministério da Saúde. Legislação em Saúde Mental 2004 a 2010. Brasília: Colegiado de Coordenadores de Saúde Mental, 2010.

BRASIL. LEI - No 11.343, de 23 de agosto de 2006. Lei Antidrogas. Institui o Sistema Nacional de Políticas Públicas sobre Drogas - SISNAD. Diário Oficial [da] República Federativa do Brasil, Poder Executivo, Brasília - DF, 24 ago. Seção 1, p. 02.2006.

BRASIL, Ministério da Saúde. OPAS/OMS e UNODC expressam preocupação com as ações sobre drogas em São Paulo. 2017. Disponível em: https:/www.paho.org/bra/images/stories/GCC/ nota_opas_unodc_28maio2017_drogas.pdf?ua=1. Acesso em: 5 dez. 2018

CARRANZA, D.V.V.; PEDRAO, L.J. Satisfação pessoal do adolescente viciado em drogas no ambiente familiar durante a fase de tratamento em um instituto de saúde mental. Rev. Latinoam. Enferm., v.13, p.836-844, 2005.

CAMPOS, M.S. Pela metade: as principais implicações da nova lei de drogas no sistema de justiça criminal em São Paulo. São Paulo: Universidade de São Paulo, 2015.

DEGASPERI, N.D. Drogas, politicas sociais e serviço social. Florianópolis: Universidade Federal de Santa Catarina, 2013.

FERREIRA, N.S.A. As pesquisas denominadas "estado da arte". Educ. Soc., v.23, n.79. p.257-272. 2002.
IAMAMOTO, M.V. O serviço social na contemporaneidade: trabalho e formação profissional. São Paulo: Cortez, 2009.

LARANJEIRA, R. Legalização de drogas e a saúde pública. Ciênc. Saúde Coletiva, v.15, n.3, p.621-631. 2010.

LEMGRUBER, J. Reincidência e reincidentes penitenciários no sistema penal do Estado do Rio de Janeiro. Rev. Esc. Serv. Penitenc. Rio Grande Sul, v.1. n.2. p.45-76. 1989.

LERMEN, H.S.; DARTORA, T.; CAPRA, R. Drogadição no cárcere: questões acerca de um projeto de desintoxicação de drogas para pessoas privadas de liberdade. Estud. Pesq. Psicol., v.14, n.2, p. 539-559. 2014.

LIMA, W.C; LIMA, W.C. Drogas, mídia e sistema prisional: uma análise criminológica. Santa Maria: UFSM, 2015.

MARTINELLI, M.L. O serviço social e a consolidação de direitos: desafios contemporâneos. Serv. Soc. Saúde, v.10. n.2. p.1-17. 2015.

SANCHES, R.R. Delenda proibicionismo: apontamentos críticos ao paradigmade guerra às drogas, 2010. Dispoonivel em: https:// repositorio.unesp.br/handle/11449/97587

TORRES, A.C; GOMES, M.C. Drogas e prisões: Relações próximas. Rev. Tóxicodep., v.11, n.2, p.23-40. 2005.

TAVARES, G; ALMEIDA, R.M.M. Violência, dependência química e transtornos mentais em presidiários. Estud. Psicol., v.27. n.4. p.545-552. 2010.

PRATES, F.P. Consumo de substâncias psicoativas em adultos do sexo masculino privados de liberdade. Santa Maria: Universidade Federal de Santa Maria, 2016.

RIBEIRO, M.A.; LARANJEIRA, R. Evolução do conceito de dependência [atualizada, com comentários sobre o DSM-5]. In: GIGLIOTTI, A.; GUIMARÃES, A. Dependência, compulsão e impulsividade. Rio de Janeiro: Rubio, 2016.

SAPORI, L.F; SANTOS, R.F; MAAS, L.W.D. Fatores sociais determinantes da reincidência criminal no Brasil: o caso de Minas Gerais. Rev. Bras. Cienc. Soc., v.32. n.94, 2017.

SANTOS, C.E.D. Politicas e práticas de cuidado da rede portuguesa de intervenção nos comportamentos aditivos e nas dependências: contribuições para o modelo brasileiro. Assis: Universidade Estadual Paulista, 2017.

IPEA. Reincidência Criminal no Brasil - Relatório de Pesquisa. 2015. Disponível em: http://www.ipea.gov.br/portal/images/ stories/PDFs/relatoriopesquisa/150611_relatorio_reincidencia_ criminal.pdf. Acesso em: 12 jan. 2019.

WORLD DRUG REPORT, United Nations publication, Sales No. E.18.XI.9. O United Nations Office on Drogs and Crime e a resposta às drogas. 2018. Disponível em:https://www.unodc.org/ lpo-brazil/pt/frontpage/2018/06/relatorio-mundial-drogas-2018. html. Acesso em: 12 jan. 2019 